\title{
INFRAESTRUTURA VERDE: SUSTENTABILIDADE E RESILIÊNCIA PARA A PAISAGEM URBANA
}

Cecilia Polacow Herzog

Paisagista, Especialista em Preservação Ambiental das Cidades, Mestre em Urbanismo, Presidente da Inverde e Conselheira da OSCIP Associação dos Amigos do Parque Nacional da Tijuca, Rio de Janeiro

cecilia@inverde.org

Rua Nina Rodrigues, 93 apt. 301, Rio de Janeiro, RJ CEP 22461-100

Lourdes Zunino Rosa

Arquiteta graduada pela U.P.6/Paris, Mestre em Conforto Ambiental pela FAU/UFRJ, Doutora em Transportes e Sustentabilidade pela COPPE/UFRJ, Diretora da OCAM, Oficina Conforto Ambiental, Diretora da Inverde

ocam@openlink.com.br

Rua João Alfredo 54 Cob. 02, Rio de Janeiro, RJ CEP 20511-390

\section{RESUMO}

As cidades são ecossistemas abertos vulneráveis a eventos climáticos. A expansão urbana voltada para o uso de automóveis leva à construção de infraestruturas cinzas (vias, estacionamentos e outras superfícies impermeáveis), que ocasionam impactos recorrentes, como enchentes e deslizamentos, congestionamentos de trânsito, alto consumo de energia, emissão de gases de efeito estufa (GEE) e poluição generalizada. Este artigo enfoca o potencial da infraestrutura verde como uma maneira de mitigar os efeitos dessa urbanização, dar resiliência aos ecossistemas urbanos para enfrentar os desafios das mudanças climáticas, além de contribuir para a transição a uma economia de baixo carbono. Infraestrutura verde num meio urbano consolidado consiste em uma rede multifuncional verde-azul (vegetação - sistemas hídrico/drenagem) que incorpora o retrofit (renovação) e adaptação da infraestrutura existente. Apresenta inicialmente um breve histórico e a seguir discorre sobre infraestrutura verde. Dois casos ilustram o seu potencial: um já implantado e consolidado em Freiburg na Alemanha, e outro uma proposição ideal para uma bacia hidrográfica urbana no 
Rio de Janeiro, Brasil. Infraestrutura verde proporciona serviços ecossistêmicos essenciais para a sustentabilidade urbana de longo prazo. Planejar, projetar e monitorar uma infraestrutura verde pode ser uma maneira de reduzir enchentes e deslizamentos, incrementar o transporte "limpo", capturar carbono, melhorar a qualidade das águas e a saúde da população com conseqüentes benefícios econômicos.

PALAVRASCHAVE: infraestrutura verde; adaptação; resiliência; sustentabilidade; serviços ecossistêmicos; baixo carbono

\title{
GREEN INFRASTRUCTURE: BUILDING SUSTAINABILITY AND RESILIENCE IN URBAN LANDSCAPES
}

\begin{abstract}
Cities are open ecosystems frequently vulnerable to climatic events. Urban sprawl based on private cars requires grey infrastructure development (roads, parking lots, and others impervious surfaces), which leads to recurrent impacts, such as floods and landslides, traffic congestion, high energy consumption, greenhouse gases emissions (GHG) and wide spread pollution. This paper focuses on the potential of green infrastructure as a means to mitigate the urbanization impacts, build resilience in urban ecosystems to face climate change challenges, besides preparing for a low carbon economy. Green infrastructure in a consolidated urban environment consists of a multifunctional green-blue (vegetated-hydric/drainage system) network which incorporates the retrofit and adaptation of existing grey infrastructure. Initially presents a brief ecological structure history, followed by a discussion about green infrastructure. Two case studies illustrate the green infrastructure potential: a consolidated one in Freiburg, Germany, and an ideal proposition for an urban watershed in Rio de Janeiro city, Brazil. Green infrastructure provides essential ecosystem services for long term urban sustainability. Planning, designing and managing green infrastructure may be a means to reduce floods and landslides, increase clean transportation, carbon sequestration, water quality and improve human health, with consequent economic benefits.
\end{abstract}

KEYWORDS: green infrastructure; adaptation; resilience; sustainability; ecosystems services; low carbon

\section{INTRODUÇÃO}

Atualmente mais de metade da população mundial mora em cidades. No Brasil são mais de oitenta por cento de pessoas morando em áreas urbanas. Os ecossistemas urbanos são sistemas abertos, dinâmicos, complexos e interrelacionados, que requerem grandes quantidades de energia e matéria, com equivalente geração de resíduos e poluição. Os seus impactos vão muito além de 
seus limites geográficos e podem ser medidos através de sua pegada ecológica ${ }^{3}$ (Beatley, 2000; Newman e Jennings, 2008; Boutaud e Gondran, 2009). A infraestrutura verde possibilita que as cidades diminuam essa pegada, ao proporcionar alternativas que consomem menos energia, não emitem gases de efeito estufa, capturam carbono, evitam a sedimentação dos corpos d'água, protegem e aumentam a biodiversidade, fornecem serviços ecossistêmicos no local, previnem ou diminuem a poluição das águas, do ar e do solo, entre outros benefícios (Elmqvist, 2010). As cidades podem ser mais compactas e proporcionar alta qualidade de vida, com espaços verdes públicos multifuncionais, bem planejados e de fácil acesso (Ahern, 2009; Owen, 2009).

A grande maioria das cidades é vulnerável a efeitos severos causados por ocorrências climáticas, que se tornam mais graves e freqüentes devido às mudanças climáticas. Contudo, mesmo durante chuvas normais as enchentes são habituais devido à urbanização em áreas inadequadas (Brandão, 2004). Áreas de risco, como encostas íngremes, topos de morros, baixadas e áreas alagáveis e margens de corpos d'água são ocupadas pelo mercado formal e informal o que leva a perdas econômicas, sociais e ambientais, e a acontecimentos muitas vezes trágicos (Coelho Netto, 2005).

As atividades humanas acontecem na paisagem onde ocorrem os processos e fluxos naturais abióticos (geológicos e hidrológicos) e bióticos (biológicos). A urbanização tradicional é baseada na infraestrutura cinza monofuncional, focada no automóvel: ruas visam à circulação de veículos; sistemas de esgotamento sanitário e drenagem objetivam se livrar da água e do esgoto o mais rápido possível; telhados servem apenas para proteger edificações e estacionamentos asfaltados são destinados a parar carros. A infraestrutura cinza interfere e bloqueia as dinâmicas naturais, que além de ocasionar conseqüências como inundações e deslizamentos, suprime áreas naturais alagadas/alagáveis e florestadas que prestam serviços ecológicos insubstituíveis em áreas urbanas (Farr, 2008; Herzog, 2009).

O planejamento de uma infraestrutura verde propicia a integração da natureza na cidade, de modo a que venha ser mais sustentável. Favorece também a mitigação de impactos ambientais e a adaptação para enfrentar os problemas causados pelas alterações climáticas, como por exemplo: chuvas mais intensas e frequentes, aumento das temperaturas (ilhas de calor), desertificação, perda de biodiversidade, só para citar alguns (Ahern, 2009; Herzog, 2010).

Este artigo visa discutir a relevância e as potencialidades de se desenvolver uma infraestrutura verde em regiões urbanas, tanto localizadas em áreas de expansão como em locais já consolidados. Inicia com a apresentação de um histórico resumido da infraestrutura ecológica desde o século XIX. Em seguida conceitua e

\footnotetext{
${ }^{3}$ Conferência de Alain Maugard: La civilisation urbaine est-elle écocompatible?, no ciclo La croissance verte, comment? em Paris, 10 de junho de 2009. Disponível em http://www.canalu.tv/producteurs/universite de tous les savoirs/dossier programmes/les conferences de I anne e 2009/developpement durable la croissance verte comment/la civilisation urbaine est elle ec ocompatible alain maugard
} 
discute os benefícios que ela pode trazer para meios urbanos. Apresenta um exemplo internacional na cidade de Freiburg, com foco em três bairros construídos recentemente. Na sequência introduz uma proposta ideal de infraestrutura verde para uma bacia de drenagem urbana na cidade do Rio de Janeiro. Conclui com reflexões sobre as possibilidades de a infraestrutura verde ser integrada a planos e projetos urbanos de modo a tornar as cidades mais sustentáveis e resilientes às mudanças climáticas e a uma economia de baixo carbono.

\section{BREVE HISTÓRICO}

$\mathrm{Na}$ última década a infraestrutura verde tem sido incorporada em planejamentos sustentáveis de longo prazo em várias cidades de muitos países. Na verdade não é um conceito novo, mas atualmente é mais abrangente e emprega conhecimentos técnico-científicos, com a utilização de ferramentas digitais de última geração. Proporciona inúmeros benefícios para que as cidades sejam não apenas mais sustentáveis, mas mais resilientes para enfrentar os efeitos causados pelas mudanças climáticas (Ahern, 2009).

Um dos primeiros trabalhos que teve o enfoque de conciliar a sustentabilidade e resiliência da paisagem urbana com o desenvolvimento da cidade foi executado nas últimas duas décadas do século XIX. Frederick Law Olmsted projetou o emblemático Emerald Necklace (Colar de Esmeraldas), em Boston (Fig.1). Esse projeto consiste numa rede de parques interligados pelas matas ciliares dos rios Stony Brook e Muddy, que foram recuperadas a fim de restabelecer a dinâmica hídrica aliada a um sistema de esgotos (Fig. 2). Atendeu diversas necessidades, uma vez que os problemas de esgotamento sanitário e industrial levaram a uma situação crítica de poluição generalizada. Essa situação era agravada pelas inundações freqüentes que causavam epidemias. É $O$ primeiro projeto de construção de áreas alagadas (wetlands) que se tem notícia. Foi feito no local com estética natural ("selvagem") e não pastoral como era comum na época. Permanece (parcialmente, pois foi cortado por avenidas) até os dias de hoje como um modelo multifuncional (Fig. 3), que alia o controle de enchentes com qualidade do ar, das águas e do solo, proteção da biodiversidade, circulação de pessoas (bicicletas e caminhadas), amenização do clima, recreação e lazer. Esse "Colar de Esmeraldas" foi o estruturador do desenvolvimento da cidade, uma infraestrutura verde pioneira. Olmsted é considerado o fundador da arquitetura paisagística que planeja e projeta a paisagem: espaços externos onde se situam os espaços construídos. Olmsted tinha uma formação multidisciplinar e em seu trabalho contemplava os processos naturais e culturais que ocorrem na paisagem (Spirn, 2002). 


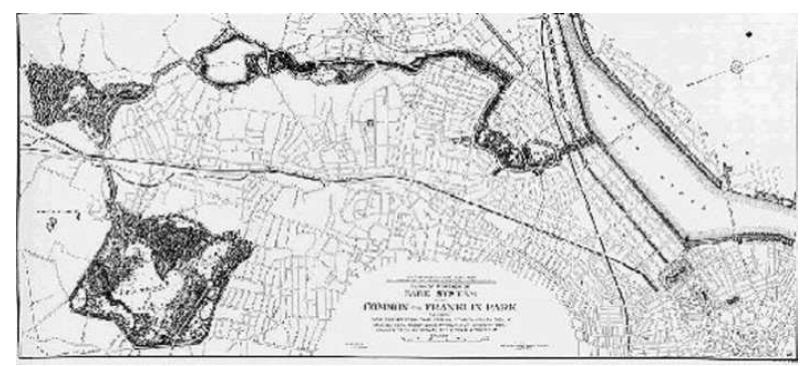

Figura 1. Plano original do Emerald Necklace, Boston, Estados Unidos ${ }^{4}$

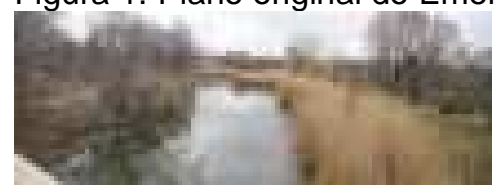

Figura 2. Parque linear (corredor verde) Fenway ao longo do rio Muddy, multifuncionalidade que abriga biodiversidade, proporciona circulação, lazer e relaxamento para os moradores em pleno centro de Boston, além de filtrar as águas poluídas e prevenir inundações. (crédito: Cecilia Herzog)

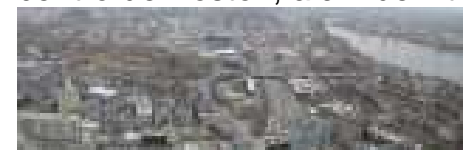

Figura 3. Parque Fenway cortado pelas vias antes de chegar ao rio Charles. (crédito: Cecilia Herzog)

Também devem ser lembrados entre muitos outros que propuseram soluções urbanas e regionais em busca de sustentabilidade, os trabalhos de Ebenezer Howard - "Gardens Cities of To-Morrow" (Cidades Jardins) (Howard, 1965, 1‥ edição 1898) e Patrick Geddes - "Cities in Evolution" (Cidades em Evolução) (Geddes, 1994, 1a. edição 1915). O primeiro propôs cidades cercadas de cinturões verdes para conter a expansão urbana, que faziam a transição com as paisagens produtivas (agrícolas). Geddes colocou em prática o processo participativo, com exposições que visavam à interação com a comunidade.

Na cidade do Rio de Janeiro é emblemático o caso do replantio de mata nativa no maciço da Tijuca ainda no século XIX pelo Major Archer, que teve por objetivo conservar os mananciais de água da cidade (Frischenbruder e Pellegrino, 2004). A floresta se regenerou ao longo do tempo e hoje mantém a temperatura da cidade mais amena. É multifuncional, permite atividades esportivas, lazer e recreação, ainda abriga sítios histórico-culturais. Além de fornecer inúmeros serviços ecológicos para a cidade e seus habitantes, como a contenção de encostas, diminuição de enchentes e abrigar uma grande biodiversidade urbana. É protegido pelo Parque Nacional da Tijuca.

No século $X X$, o enfoque no desenvolvimento urbano baseado nos automóveis levou ao espraiamento urbano sobre áreas que deveriam ter sido preservadas, como margens de corpos d'água, encostas íngremes, baixadas e áreas alagadas, ecossistemas naturais que fornecem serviços ecológicos essenciais para a sustentabilidade das cidades (Hough, 1994).

\footnotetext{
${ }^{4}$ Disponível em http://www.archives.gov/nhprc/annotation/september-98/images/emeraldnecklace.jpg acesso em 20 de julho de 2010
} 
Em 1969 lan McHarg lançou o livro seminal Design with Nature, que sistematizou o levantamento do suporte natural (geobiofísico) e os usos e ocupações humanos que ocorrem nesse suporte. Demonstrou como utilizava mapas temáticos (em acetato para que fossem sobrepostos) de modo a identificar as áreas mais suscetíveis ecologicamente e as mais adequadas à ocupação (McHarg 1969). Não foi pioneiro em propor essa técnica, nem em planejar a paisagem baseado na multidisciplinaridade, mas deu uma grande contribuição ao dar destaque à ecologia. A partir de então a prática de levantar os aspectos naturais e culturais se tornaram correntes no ensino e prática de planejamento e projeto da paisagem em áreas urbanas e rurais (Spirn, 2002).

O desenvolvimento da ecologia da paisagem (Forman e Godron, 1986; Forman, 1995), que se desdobrou em ecologia urbana nos últimos anos levou ao entendimento de que a interação entre as pessoas e a natureza pode levar a uma mudança positiva no planejamento e adaptação das cidades (Alberti, 2008; Marzluff, 2008; Elmqvist, 2010; Forman, 2010). As novas tecnologias para levantamento e mapeamento da paisagem são ferramentas fundamentais para desenvolver uma infraestrutura verde eficaz e eficiente (Almeida et al., 2007).

Em 2006, Benedict e McMahon lançaram o livro Green Infrastructure - Linking landscapes and communities (Benedict e McMahon, 2006), que organizou 0 conhecimento e deu evidência às potencialidades da infraestrutura verde em diversas escalas.

\section{SOBRE INFRAESTRUTURA VERDE}

A infraestrutura verde consiste em redes multifuncionais de fragmentos permeáveis e vegetados, preferencialmente arborizados (inclui ruas e propriedades públicas e privadas), interconectados que reestruturam o mosaico da paisagem. Visa manter ou restabelecer os processos naturais e culturais que asseguram a qualidade de vida urbana (Benedict e McMahon, 2006; Ahern, 2007). A infraestrutura verde, também chamada de infraestrutura ecológica (Yu e Padua, 2006; Ignatieva, 2010) é um conceito emergente baseado nos princípios da ecologia da paisagem de: estrutura, função e mudança. A forma do mosaico da paisagem depende não apenas de seus aspectos geobiofísicos, mas do uso e ocupação ao longo do tempo (Forman, 1995; Benedict e McMahon, 2006; Ahern, 2007).

As árvores, essenciais na infraestrutura verde, têm funções ecológicas insubstituíveis, como: contribuir significativamente para prevenir erosão e assoreamento de corpos d'água; promover a infiltração das águas das chuvas, reduzindo o impacto das gotas que compactam o solo; capturar gases de efeito estufa; ser habitat para diversas espécies promovendo a biodiversidade, mitigar efeitos de ilhas de calor, para citar algumas. A floresta urbana consiste no somatório de todas as árvores que se encontram na cidade, em parques e praças, ruas e fragmentos de matas (Hough, 1984 e 1994; Newman et al., 2009). O ideal é conectar estes espaços para que integrem uma infraestrutura verde. Por exemplo, parques arborizados podem ser articulados por conexões lineares como ruas verdes. Conexão é fundamental para os fluxos de água, biodiversidade e pessoas 
(Forman, 1995; Benedict e McMahon, 2006; Ahern, 2007). A infraestrutura verde proporciona serviços ecossistêmicos ao mimetizar as funções naturais da paisagem, visa conservar e restaurar áreas ecológicas relevantes. O conceito é fazer a cidade funcionar como uma floresta e cada edifício como uma árvore (Beatley, 2000; McDonough e Braumgart, 2002).

As atividades humanas acontecem na paisagem onde ocorrem os processos e fluxos naturais abióticos (geológicos e hidrológicos) e bióticos (biológicos - fauna e flora). A infraestrutura verde compreende e analisa esses processos através de seis sistemas ${ }^{5}$, como segue:

- Naturais: geológico, hidrológico, biológico,

- Antrópicos/Culturais: social, circulatório e metabólico.

Os sistemas naturais se constituem na base onde os sistemas antrópicos/culturais se desenvolvem. Ou seja, como as pessoas usam e interferem no espaço: como acontece a interação social, de que forma ocorrem os fluxos de circulação (carros, ônibus, pedestres, bicicletas, trens, VLT's etc.), de energia (elétrica e combustíveis diversos) e matéria (comida e outros insumos, esgoto e resíduos sólidos).

A infraestrutura verde consiste em intervenções de baixo impacto na paisagem e alto desempenho, com espaços multifuncionais e flexíveis, que possam exercer diferentes funções ao longo do tempo - adaptável às necessidades futuras. Pode ser implantada em experiências locais que sejam safe-to-fail (seguras-para-falhar), sendo monitoradas para possíveis correções ao longo do tempo (Ahern, 2009). Visa também, buscar oportunidades de transportes alternativos não poluentes que estimulam uma vida urbana ativa e saudável, e promover o uso de energias renováveis sempre que possível. Esses espaços ganhos dos veículos são devolvidos para os cidadãos para que ruas voltem a ser lugares vivos, de encontros sociais e com comércio e serviços ativos (Jacobs, 1992). O planejamento da infraestrutura verde integra os diversos meios de transporte, de maneira a permitir que pedestres e bicicletas utilizem transporte de massa de forma bem articulada e confortável. A inserção de paisagens urbanas produtivas agricultura urbana em diversas escalas e agroflorestas -, deve ser considerada no planejamento da infraestrutura ecológica urbana, e incentivada em todos os locais possíveis (Beatley, 2000; Herzog, 2010; Imberti, 2010).

Bem planejada, implementada e monitorada a infraestrutura verde pode se constituir no suporte para a resiliência das cidades. Pode ser um meio de adaptar e regenerar o tecido urbano de modo a torná-lo resiliente aos impactos causados pelas mudanças climáticas e também preparar para uma economia de baixo carbono. Ela aumenta a capacidade de resposta e recuperação a eventos climáticos, propicia mudança das fontes de energias poluentes ou de alto custo para fontes renováveis, promove a produção de alimentos perto da fonte

\footnotetext{
5 "Planning Urban Green Infrastructure Networks" - Curso à distância feito pela autora na Universidade de Washington, com os professores Nate Cormier e Brice Maryman.
} 
consumidora, além de melhorar a saúde de seus habitantes ao possibilitar transportes ativos como caminhada e bicicleta (Herzog, 2010).

Para que o planejamento e projeto da infraestrutura verde sejam de fato eficientes e eficazes, é preciso ter uma abordagem sistêmica, abrangente e transdisciplinar. Depende de um levantamento detalhado dos aspectos abióticos, bióticos e culturais. Inicialmente é preciso fazer um mapeamento dos condicionantes geológicos, geomorfológicos, hídricos (de preferência ter a bacia hidrográfica como unidade de macroplanejamento), climáticos, da cobertura vegetal, dos sistemas de drenagem e esgotamento sanitário, e uso e ocupação do solo. Também é importante conhecer a biodiversidade local. Levantar dados e mapas históricos de uso e ocupação do solo, de hábitos e da cultura local. Conhecer o mais profundamente o lugar. O processo deve ser dinâmico e flexível, além de efetivamente participativo contando com representantes de todos os segmentos da sociedade que serão afetados pelo projeto. É necessário identificar os anseios e problemas trazidos pela comunidade, em busca de novas idéias fruto da vivência e experiência do lugar. Esse engajamento dos usuários no desenvolvimento do planejamento e projeto é essencial para que a infraestrutura verde seja sustentável no longo prazo (Ribeiro, 2001; Boucinhas, 2007; Costa et al., 2007). O diagnóstico irá indicar quais as oportunidades e as limitações da área.

Idealmente, a infraestrutura verde deve ser planejada antes da ocupação, assim áreas frágeis e de grande valor ambiental podem ser conservadas, como: áreas alagadas, corredores ripários, encostas instáveis com risco de deslizamento e fragmentos de ecossistemas nativos. A integração desses espaços na infraestrutura verde irá garantir a manutenção dos serviços ecossistêmicos (ver quadro de serviços ecossistêmicos), como água e ar limpos, estabilização de encostas de forma natural, prevenção de enchentes e deslizamentos, conexão de fluxos hídricos e bióticos, prevenção de assoreamento entre outros (Bolund, 1999; Herzog, 2009; Elmqvist, 2010)

Tabela 1 Quadro de serviços ecossistêmicos (Ahern, 20086 $)$

\begin{tabular}{|c|c|c|}
\hline Processos & Biófito remediação de & Oportunidade \\
\hline $\begin{array}{l}\text { A(Bbsefiticolsimento } \\
\text { solos } \\
\text { (geofísicos) }\end{array}$ & $\begin{array}{l}\text { Bif́́fteos sólidos e } \\
\text { tóxicos }\end{array}$ & 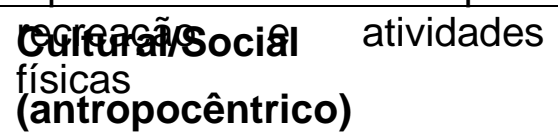 \\
\hline 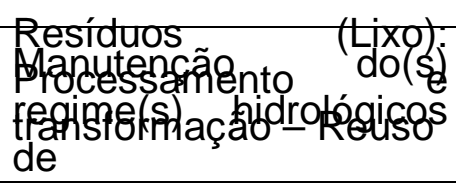 & 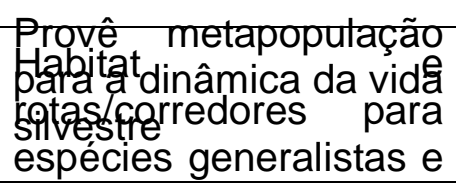 & $\begin{array}{l}\text { Benefícios específicos para } \\
\text { Supartes putharteg integrante de } \\
\text { atividades econômicas }\end{array}$ \\
\hline 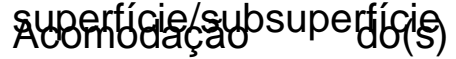 & 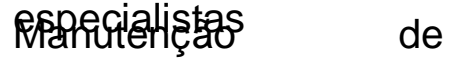 & Proporciona um sentimento \\
\hline regime(s) de distúrbios & $\begin{array}{l}\text { distúrbios e regime(s) } \\
\text { de sucessão }\end{array}$ & $\begin{array}{l}\text { de isolamento, paz e } \\
\text { inspiração }\end{array}$ \\
\hline
\end{tabular}

\footnotetext{
${ }^{6}$ Palestra do Dr. Jack Ahern: "Infraestrutura Verde para uma cidade Sustentável”, promovida pela Inverde, no Rio de Janeiro, em 8 de dezembro de 2008.
} 


\begin{tabular}{|c|c|c|}
\hline $\begin{array}{l}\text { Ciclagem de nutrientes } \\
-\quad \text { amortecimento } \\
\text { sequestro }\end{array}$ & Produção de Biomassa & $\begin{array}{l}\text { Contexto saudável } \\
\text { interações sociais }\end{array}$ \\
\hline $\begin{array}{l}\text { Proteção } \\
\text { Amortecimento de } \\
\text { Enchentes }\end{array}$ & $\begin{array}{l}\text { "Reservatório de } \\
\text { diversidade genética }\end{array}$ & $\begin{array}{l}\text { Estímulo para expressão } \\
\text { artística e abstrata }\end{array}$ \\
\hline $\begin{array}{l}\text { Alteração, } \\
\text { amortecimento de } \\
\text { extremos climáticos }\end{array}$ & $\begin{array}{l}\text { Base para interações } \\
\text { de Flora e Fauna }\end{array}$ & $\begin{array}{l}\text { Possibilita } \\
\text { Ambiental }\end{array}$ \\
\hline
\end{tabular}

$\mathrm{Na}$ escala local tipologias multifuncionais de infra-estrutura verde têm sido desenvolvidas de modo a manter ou restabelecer as dinâmicas naturais dos fluxos hídricos e bióticos, bem como melhorar e estimular a circulação e o conforto das pessoas, e a redução do consumo de energia. Alguns exemplos são os jardins-de-chuva, biovaletas, lagoas de infiltração (bacias de detenção) e pluviais (bacias de retenção), tetos e muros verdes, alagados construídos, bioengenharia em taludes e encostas, pisos drenantes, entre outras. As tipologias podem ser combinadas e utilizadas em projetos de "escolas verdes" 7 , "ruas verdes" 8 e "ruas completas" ${ }^{9}$ (ou de múltiplo uso) ${ }^{10}$, de estacionamentos drenantes, parques lineares (corredores verdes), renaturalização de corpos d'água, para citar algumas possibilidades (Girling e Kellett, 2005; Kinkade-Levario, 2007; Dunnet e Clayden, 2007; Ignatieva et al. 2008; Cormier e Pellegrino, 2008; Thompson e Sorvig, 2008, entre outros).

7 GSI. Green Schools Initiative . Disponível em http://www.greenschools.net/ acesso em 13.08.2009.

${ }^{8}$ São ruas arborizadas, que integram o manejo de águas pluviais (com canteiros pluviais), reduz o escoamento superficial durante o período das chuvas, diminui a poluição difusa que é carreada de superfícies impermeabilizadas, possibilita dar visibilidade aos processos hidrológicos e do funcionamento da infra-estrutura verde. A circulação viária é mais restrita, com preferência para pedestres e ciclistas, não há trânsito de veículos pesados. As travessias são bem demarcadas com piso diferenciado e traffic calming (Girling e Kellett, 2005; Kinkade-Levario, 2007; Ignatieva et al. 2008).

${ }^{9}$ San Francisco Planning Department - SFPD. Better Streets Plan de 2006 - acesso em 21_03_2009. Edição: disponível em http://www.sfgov.org/site/uploadedfiles/planning/Citywide/Better_Streets/index.htm. acesso em 05 de março de 2010.

10 São vias que conciliam diversos usos além de veículos e pedestres. Possibilitam ciclovias seguras e independentes do tráfego viário e das calçadas. Os cruzamentos para pedestres e ciclistas devem ser prioritários, bem marcados com traffic calming (lombadas estendidas para diminuir a velocidade dos veículos). As paradas de ônibus devem ter recuos seguros, com abrigos e mobiliário urbano compatível. Podem acomodar bancos, áreas com mesas de bares e restaurantes, bancas de jornal, telefones públicos. Devem ser compatibilizadas com os processos naturais como drenagem das águas pluviais, biodiversidade, amenização das ilhas de calor e sombreamento para os usuários. Para isso devem contar como arborização intensa, e diversas tipologias, como: canteiros pluviais, biovaletas, interseções viárias entre outras (SFPD; CSC). 
São inúmeros benefícios prestados pela incorporação dessas tipologias na infraestrutura da cidade, como: promover a infiltração, detenção e retenção das águas das chuvas no local, evitando o escoamento superficial; filtrar as águas de escoamento superficial nos primeiros 10 minutos da chuva, provenientes de calçadas e vias pavimentadas contaminadas por resíduos de óleo, borracha de pneu e partículas de poluição; criar habitat e conectividade para a biodiversidade; amenizar as temperaturas internas em edificações e mitigar as ilhas de calor; promover a circulação de pedestres e bicicletas em ambientes sombreados, agradáveis e seguros; diminuir a velocidade dos veículos; conter encostas e margens de cursos d'água para evitar deslizamentos e assoreamento. As tipologias devem ser incluídas em planejamentos e projetos, devendo ser incorporadas às áreas já urbanizadas, quando houver oportunidades como reformas, renovações e adaptações das edificações e demais espaços impermeabilizados existentes (retrofit) ${ }^{11}$.

\section{CASO INTERNACIONAL: FREIBURG}

No sul da Alemanha, a cidade de Freiburg ${ }^{12}$ além de ser um modelo de cidade compacta que utiliza energia limpa com prioridade para transportes não poluentes é também exemplo de infraestrutura verde. O eixo principal de conexão de ciclistas e pedestres cruza a cidade ao longo do rio por $9,5 \mathrm{Km}$, é um corredor verde multifuncional (Fig.4). Possui plano de infraestrutura verde em duas escalas. $\mathrm{Na}$ escala urbana tem uma rede de áreas de conservação e agrícolas que entremeiam as áreas urbanizadas. Na escala local trabalha junto com os proprietários para manter a integração com o plano na escala da paisagem. As regras construtivas são bastante restritivas, não são apenas parâmetros máximos e mínimos ${ }^{13}$.

\footnotetext{
${ }^{11}$ Palestra do Dr. Jack Ahern: "Infraestrutura Verde para uma cidade Sustentável", promovida pela Inverde, no Rio de Janeiro, em 8 de dezembro de 2008.

${ }^{12}$ Cidade visitada pela autora em junho de 2010.

${ }^{13}$ Comunicação pessoal com Sabine Gunst e Sabine Gilcher, paisagistas e planejadoras urbanas que moram e trabalham na cidade e na região, em junho de 2010.
} 


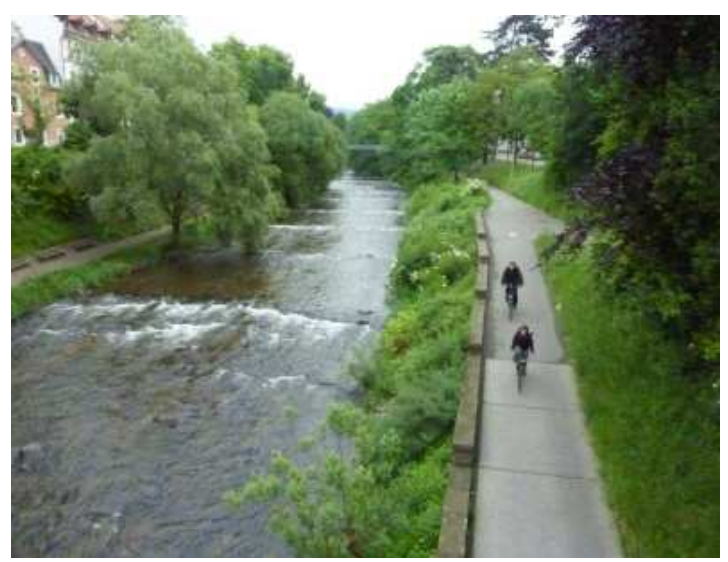

Figura 4. Corredor verde multifuncional (parque linear) de 9,5 Km em Freiburg. (crédito: Cecilia Herzog)

O planejamento urbano nas últimas duas décadas foi desenvolvido tomando como referência os problemas causados por ocupações mal planejadas anteriormente "aprendeu planejando" (Newman et al., 2009). A articulação dos meios de transporte de baixo impacto pode ser conferida no edifício verde (utiliza energia solar) onde os ciclistas guardam as bicicletas (Fig. 5 e 6) para pegar o VLT, trens ou ônibus situados na estação central multimodal que abriga hotel, comércio, serviços e escritórios ${ }^{14}$.

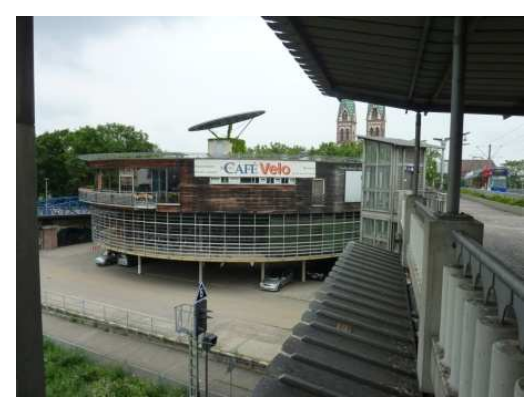

Figura 5. Freiburg. Vista do edifício garagem de bicicletas do viaduto por onde passa o VLT, sobre as linhas de trem. (crédito: Cecilia Herzog)

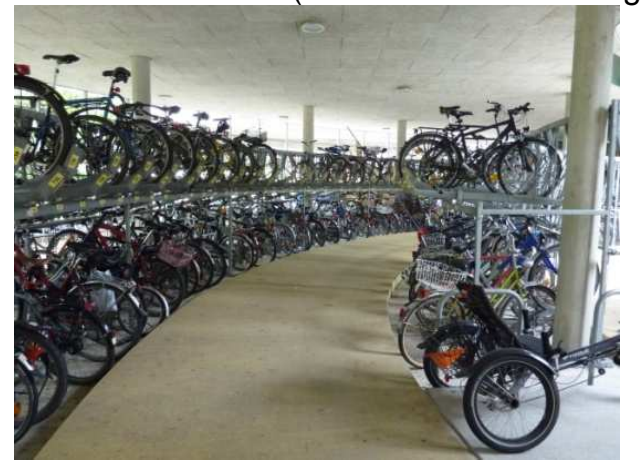

Figura 6. Freiburg. Interior do edifício garagem. (crédito: Cecilia Herzog)

${ }^{14}$ Idem 
O bairro de Rieselfeld ${ }^{15}$ foi criado onde antes era o destino de todo o esgoto da cidade durante anos (Figuras 7 a 11). Um cinturão verde, que tem áreas de preservação e rurais, foi projetado para garantir a qualidade de vida do local e abrigar vida silvestre. A drenagem é toda naturalizada, com uma sucessão de jardins, biovaletas, lagoas de retenção e detenção, vai das edificações até a lagoa de detenção localizada na reserva ecológica. Uma pista de bicicletas e pedestres passa pela periferia do bairro e permite circular até o centro da cidade e o interior do cinturão onde está localizado um zoológico.

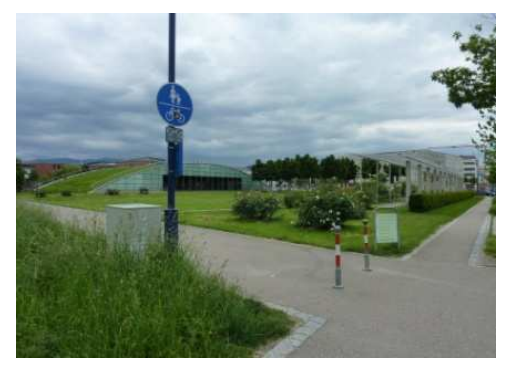

Figura 7. Parque urbano no centro de Rieselfeld, Freiburg. A construção com teto verde abriga quadras poliesportivas em meio a diversos espaços para lazer, recreação e cultura. (crédito: Cecilia Herzog)

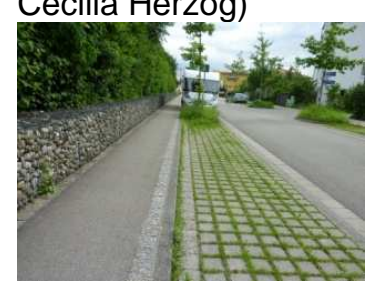

Figura 8. Estacionamento e pavimentação drenantes, Rieselfeld, Freiburg, Alemanha. (crédito: Cecilia Herzog)

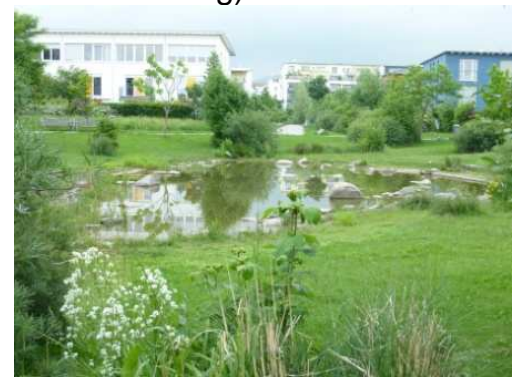

Figura 9. Lagoa pluvial - integra o sistema de drenagem naturalizado do bairro de Rieselfeld, Freiburg, Alemanha. (crédito: Cecilia Herzog)

\footnotetext{
${ }^{15}$ Disponível em http://www.williemiller.co.uk/remarkable-rieselfeld.htm acesso em 24 de junho de 2010.
} 


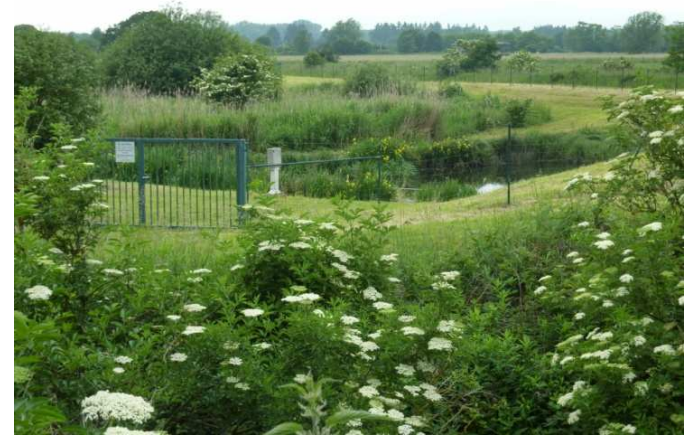

Figura 10. Lagoa Seca (ou de infiltração), Rieselfeld, Freiburg, Alemanha. Localizada no final do sistema natural de drenagem do bairro dentro da reserva ecológica, recebe o excedente do escoamento de águas das chuvas que não foram infiltrados durante o percurso. (crédito: Cecilia Herzog)

Vauban, outro bairro de Freiburg é um projeto mais recente (Figuras 12 a 17). $\mathrm{O}$ planejamento de sua paisagem visou também ser de baixo impacto e alto desempenho. O bairro é compacto na ocupação com áreas de lazer e recreação situadas entre os edifícios (Beatley, 2000; Newman et al., 2009). As superfícies são permeáveis, com sistema de drenagem que mimetiza os processos naturais. As ruas são projetadas para bicicletas e pedestres, com os estacionamentos para carros situados em edifícios-garagem na periferia. A maioria de seus moradores não possui automóvel ${ }^{16}$.

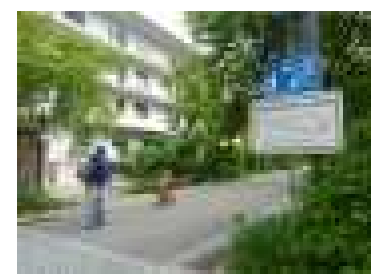

Figura 11. Vauban, Freiburg. Rua verde com biovaletas, prioridade para pedestres e ciclistas (crédito: Cecilia Herzog)

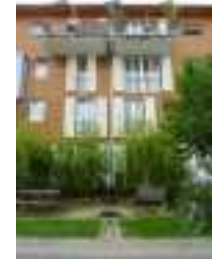

Figura 12. Vauban, Freiburg. Drenagem dos telhados conduzida por piso poroso para infiltração em chuvas normais. (crédito: Cecilia Herzog)

\footnotetext{
${ }^{16}$ Comunicação pessoal com Sabine Gunst e Sabine Gilcher, paisagistas e planejadoras urbanas que moram e trabalham na cidade e na região, em junho de 2010.
} 


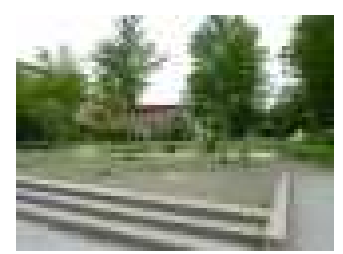

Figura 13. Vauban, Freiburg. Parque entre conjuntos de prédios de quatro andares. (crédito: Cecilia Herzog)

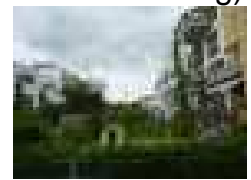

Figura 14. Vauban, Freiburg. Pátio interno privativo moradores. (crédito: Cecilia Herzog)

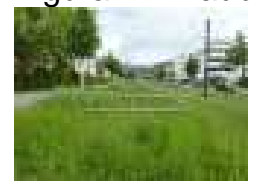

Figura 15. Vauban, Freiburg. Biovaleta ao longo dos trilhos do VLT que corre sobre área vegetada. (crédito: Cecilia Herzog)

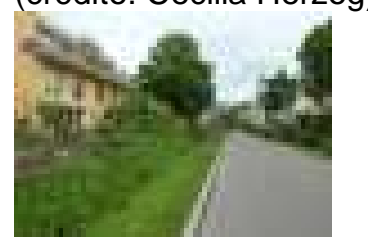

Figura 16. Vauban, Freiburg. Biovaleta ao longo da rua é o jardim em frente dos edifícios. (crédito: Cecilia Herzog)

Nos dois bairros, Rieselfeld e Vauban, o tram, ou bonde moderno (VLT) foi projetado antes do início da construção das casas. Conecta os bairros com o resto da cidade, e integra a infraestrutura verde, pois o pavimento é poroso e tem áreas com relvado (Fig. 11). É um exemplo de multifuncionalidade aliada a um meio de transporte de massa. A energia solar é visível em quase todos os lugares de Freiburg, o que ocorre até mesmo em pequenas cidades no interior da Alemanha.

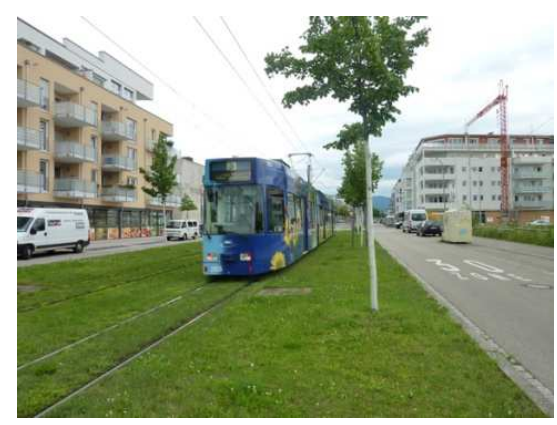

Figura 17. Rieselfeld - VTL sobre relvado. (crédito: Cecilia Herzog)

Outra área da cidade onde se introduziu o estado-da-arte em infraestrutura verde multifuncional, com drenagem urbana naturalizada, foi o loteamento residencial a oeste da estação de trens de Wiehre (Figuras 18 a 22). Esse novo empreendimento é fruto de diversas edificações feitas por diferentes empresas, 
com projetos arquitetônicos distintos, mas todos integrados à estrutura ecológica local. O sistema de drenagem aproveitou a topografia, é visível desde as áreas mais elevadas até o canteiro central em local mais baixo. Possui jardins de chuva, tetos verdes, biovaletas e na área em declive, uma sequência de pequenos diques detém as águas das chuvas (ver fotos). A área é lindeira a um parque que protege a Floresta Negra. Com isso, também conecta as áreas verdes urbanas com as áreas naturais do entorno da cidade.

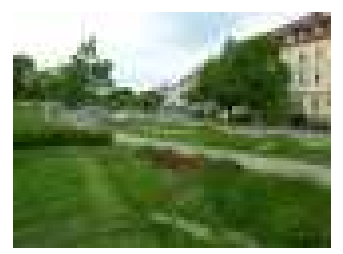

Figura 18. Biovaleta conectada com biovaleta em níveis mais abaixo na rede de drenagem naturalizada, Wiehre, Freiburg, Alemanha. (crédito: Cecilia Herzog)

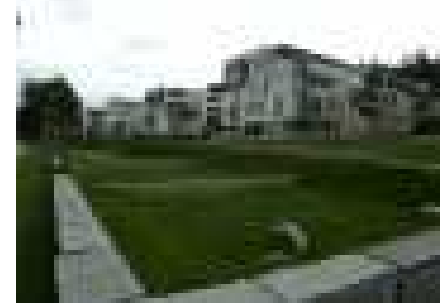

Figura 19. Wiehre. Bacia de detenção com diques em degraus no final do sistema de drenagem naturalizado, Freiburg, Alemanha. (crédito: Cecilia Herzog)

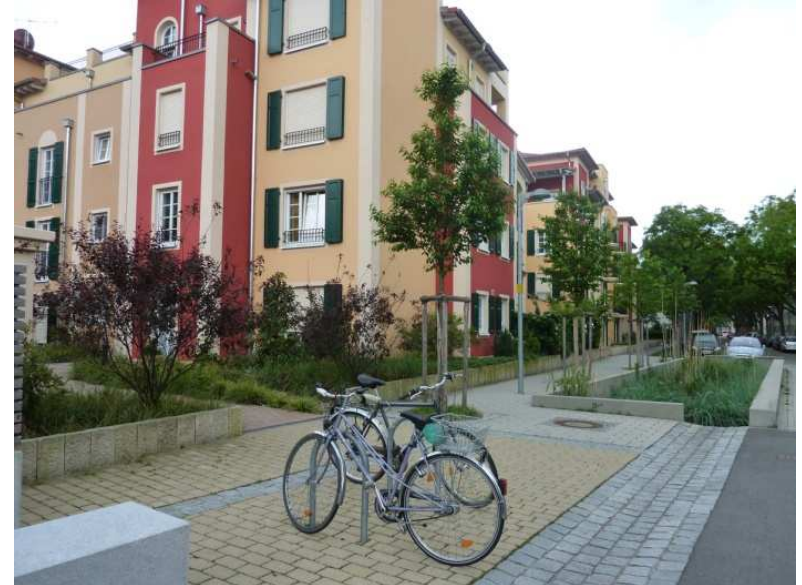

Figura 20. Wiehre - Canteiro pluvial. (crédito: Cecilia Herzog) 


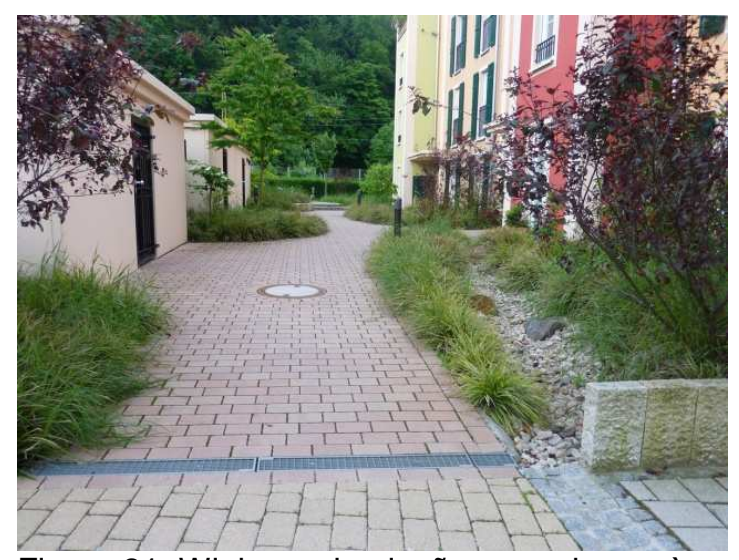

Figura 21. Wiehre - circulação para chegar às residências, com a drenagem naturalizada visível. Carros não chegam às ruas internas. (crédito: Cecilia Herzog)

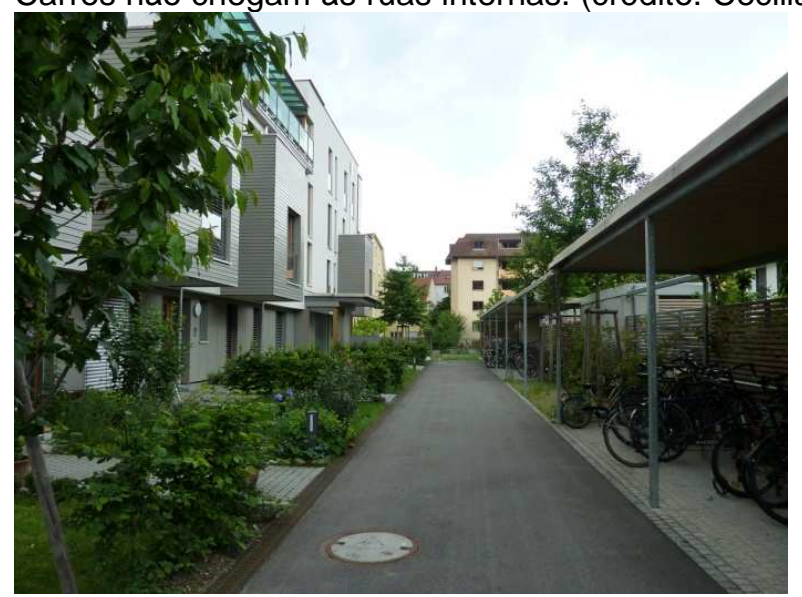

Figura 22. Wiehre - vista da rua com as residências e o estacionamento de bicicletas que possuem tetos verdes, na maioria. (crédito: Cecilia Herzog)

Freiburg atrai visitantes de todo o mundo por ser uma das cidades pioneiras em pesquisas e projetos urbanos sustentáveis, além de ter um centro histórico que foi todo restaurado e deu visibilidade para as águas até em suas estreitas ruas centrais de pedestres (Fig. 23). É um modelo de desenvolvimento voltado para a economia verde, que atrai empresas de ponta em diversos setores e pessoas em busca de melhor qualidade de vida.

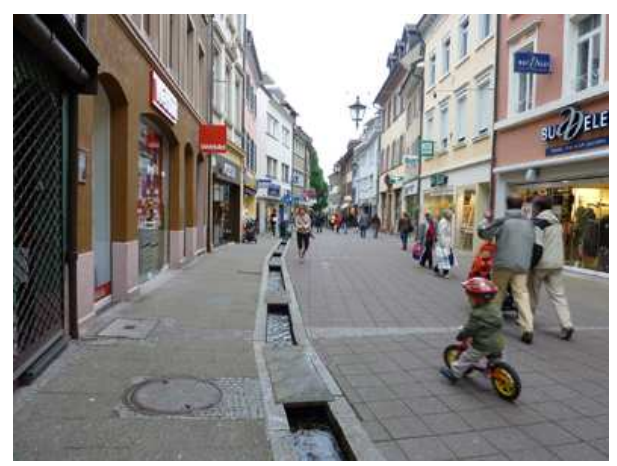

Figura 23. Freiburg. Rua reurbanizada no centro antigo, visibilidade para o fluxo das águas. (crédito: Cecilia Herzog)

CASO NACIONAL: RIO+VERDE 
A organização Inverde ${ }^{17}$ desenvolveu uma proposta ideal de infraestrutura verde para uma bacia hidrográfica urbana na cidade do Rio de Janeiro. Essa área compreende uma miríade de situações representativas do que ocorre em outras áreas da cidade. Foi escolhida também pela sua alta visibilidade por concentrar inúmeras atrações turísticas e culturais.

\section{SITUAÇÃO ATUAL}

A bacia de drenagem é cercada pelas florestas protegidas pelo Parque Nacional da Tijuca (Fig. 24). No alto do rio dos Macacos se localizam as instalações desativadas de tratamento de águas da cidade. Existem áreas urbanizadas e ocupadas irregularmente nas margens do rio, tanto formais quanto informais. $O$ Jardim Botânico encontra o Parque Nacional da Tijuca nessa zona, onde existem questões fundiárias que estão em processo de litígio há anos. Nas encostas ao norte, que estão em frente ao Jardim Botânico, residências de classes de poder aquisitivo elevado estão localizadas nas partes mais altas. Edificações históricas estão mais abaixo no vale, onde se situam residências de todos os padrões, com comércio e serviços na rua principal - Pacheco Leão. Hoje esse trecho é chamado de Soho carioca, por atrair artesãos e artistas. As áreas urbanizadas de toda a bacia são muito impermeabilizadas, com os quintais e demais áreas livres pavimentados (são frequentemente lavados com mangueira e produtos químicos, o que piora a poluição difusa das águas da bacia).

O rio dos Macacos desce canalizado por dentro do Jardim Botânico. As zonas baixas em torno do entroncamento das ruas Pacheco Leão e Jardim Botânico sofrem inundações freqüentes a cada chuva mais intensa. É onde o canalizado rio dos Macacos passa por baixo da via e sai em um canal impermeável que possui uma comporta que controla seu fluxo para a lagoa Rodrigo de Freitas. Nesse ponto há um entroncamento com o canal que atravessa o Jockey Club (Hipódromo), com uma área central não utilizada. Esse canal se encontra poluído por resíduos provenientes principalmente do próprio clube.

A Lagoa Rodrigo de Freitas e os canais se encontram assoreados e estão sendo dragados, porém as causas da sedimentação não estão sendo resolvidas. As margens da lagoa Rodrigo de Freitas possuem partes em concreto, e em outras os taludes estão em processo erosivo. O parque Tom Jobim está com seus jardins degradados, com árvores de espécies exóticas e invasoras. O grande movimento dos freqüentadores fica mais restrito à orla da Lagoa onde se situam os quiosques de alimentação, com espaços internos subutilizados. Existe uma área pública que foi privatizada e hoje abriga uma academia de ginástica de elite no entorno da Lagoa. Essa área possui extensas superfícies impermeabilizadas.

A circulação de veículos é privilegiada em detrimento dos pedestres e bicicletas. Os cruzamentos são perigosos com sinais localizados fora dos locais onde a circulação de baixo impacto ocorre de fato. As faixas compartilhadas de bicicletas e pedestres são estreitas, com riscos de acidentes. As pistas e calçadas não

\footnotetext{
${ }^{17}$ Organização sem fins lucrativos, composta por um grupo voluntário multidisciplinar. É ligada à Associação dos Amigos do Parque Nacional da Tijuca.
} 
possuem sombreamento adequado ao clima tropical, o que prejudica um maior fluxo desses meios de transporte.

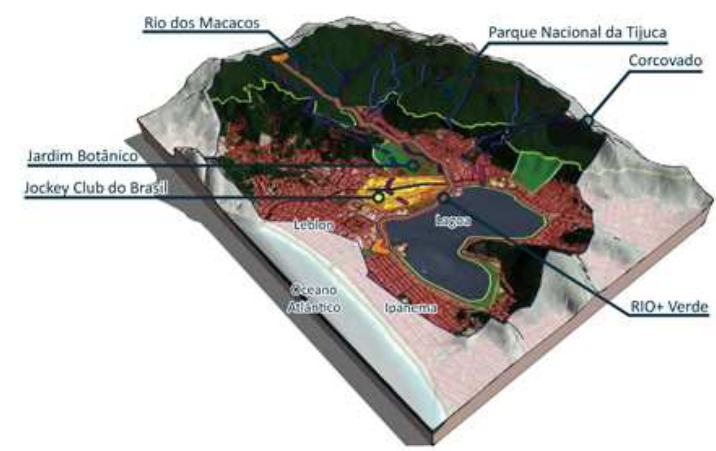

Figura 24. Inserção da bacia do rio dos Macacos na Lagoa Rodrigo de Freitas. (crédito: Inverde)

\section{PROPOSTA RIO+VERDE}

A proposição contempla uma infraestrutura verde multifuncional (Fig. 25) onde existem remanescentes de três ecossistemas locais: Floresta Pluvial, Restinga e Mangue (foi introduzido na Lagoa para melhorar as condições das águas e aumentar a biodiversidade nativa).

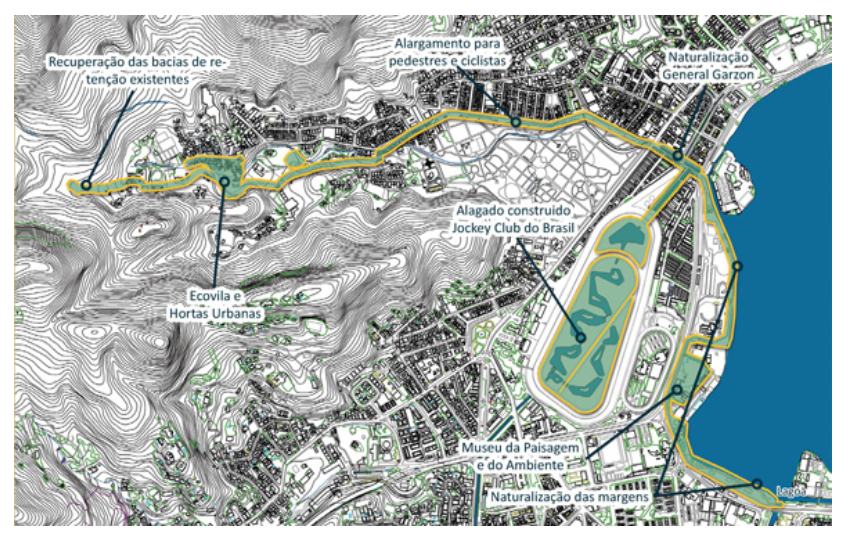

Figura 25. Percurso Rio+Verde (crédito: Inverde)

O Rio+Verde tem alguns objetivos principais, são eles: aumentar a permeabilidade do solo; deter e reter as águas da chuva no local; melhorar ou restabelecer a conectividade abiótica (águas), biótica (biodiversidade) e das pessoas (pedestres e bicicletas); reduzir o assoreamento dos corpos d'água; moderar as enchentes; incrementar a biodiversidade nativa; amenizar as ilhas de calor; dar visibilidade aos processos naturais; possibilitar a circulação de baixo impacto da comunidade local e melhorar acessibilidade aos pontos turísticos e culturais. A área foi setorizada para possibilitar proposições específicas para cada local, como segue:

- Nascente e encosta florestada: melhoria e manutenção de trilhas, instalação de lagoas pluviais e secas, recuperação de antigas instalações de tratamento de água abandonadas como ponto de atração de percurso ecológico-cultural. 
- Encosta urbanizada ao longo do rio dos Macacos: Relocação da ocupação informal nas margens (Áreas de Preservação Permanente APP) do Rio dos Macacos e recuperação da mata ciliar. Assentamento formal em pequenos prédios com princípios bioclimáticos, saneamento biológico, compostagem, lagoas pluviais e secas, campos esportivos drenantes. Para conter a expansão urbana na zona tampão do Parque: hortas, agrofloresta, trilhas marginais nas zonas tampão do parque.

- Baixada e encosta urbanizada no lado norte: desimpermeabilização de áreas pavimentadas e construídas com pisos drenantes, tetos e muros verdes, jardins-de-chuva, biovaletas, entre outras tipologias. Melhorias nas calçadas de pedestres e pistas exclusivas para bicicletas ao longo da rua principal.

- Foz e várzea: renaturalização dos canais (Fig. 26) com utilização de técnicas de bioengenharia, criação de um pequeno parque linear exclusivo para pedestres e ciclistas para melhorar a conectividade, sinalização das travessias, biovaletas e alagado construído dentro do hipódromo.

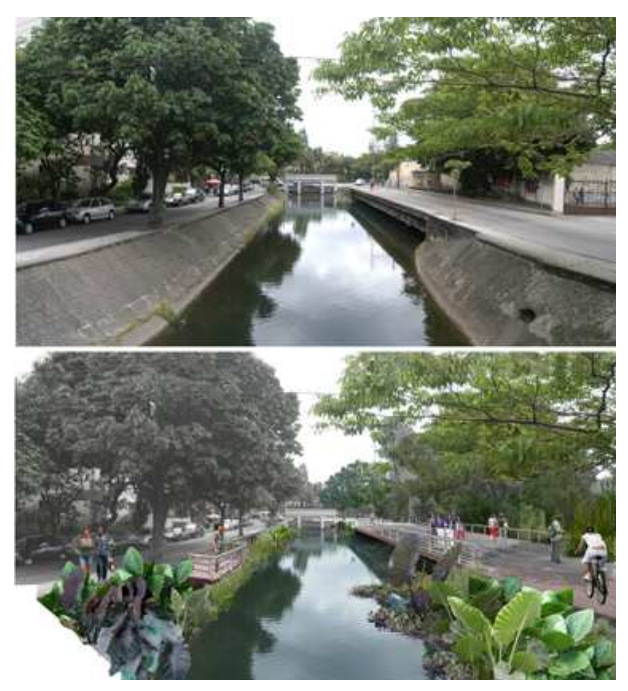

Figura 26. Renaturalização do canal dos Macacos. Antes e Depois. (crédito: Inverde)

- Orla lagunar: estacionamentos com pavimentação permeável, canteiros pluviais, biovaletas, renaturalização da margem da Lagoa, arquibancada drenante, passarela para observação da paisagem e do mangue (Fig. 27). $\mathrm{Na}$ área ocupada pela academia de ginástica implantar o Museu da Paisagem Natural e Cultural do Rio de Janeiro, focado em exposições, pesquisa e educação sobre a história e os processos naturais e culturais da ocupação urbana da paisagem da cidade. 


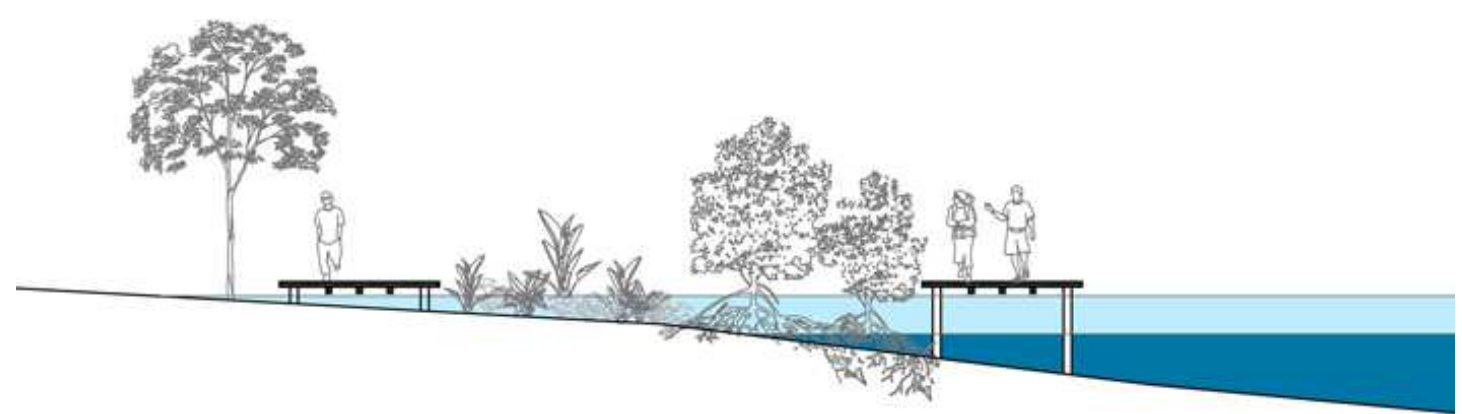

Figura 27. Passarela sobre área alagável e dando a volta por fora do mangue com vista para a Lagoa. (crédito: Inverde)

- Canal lagoa-mar: melhoria dos acessos ao parque e às ciclovias, dos cruzamentos com as vias de grande fluxo de veículos, renaturalização das margens, pavimentação permeável e jardins de chuva.

A proposta traz inúmeros benefícios para as pessoas, a biodiversidade e a qualidade das águas, como: melhoria do transporte alternativo de baixo impacto (bicicletas e pedestres); infiltração e detenção das águas das chuvas ao longo da bacia; filtragem das águas antes de entrar no sistema de águas pluviais; incremento da biodiversidade nativa; educar e dar visibilidade aos processos naturais e ecossistemas nativos; a implantação de um projeto contemporâneo que renova e valoriza as margens da Lagoa, com a atração de mais visitantes e maior geração renda para a cidade, entre outros.

\section{CONSIDERAÇÕES FINAIS}

Cidades de diversos países estão em busca de melhores condições de vida para seus habitantes e de formas de desenvolvimento que consideram a integração de áreas naturais e biodiversidade nos densos meios urbanos. A infraestrutura verde tem sido um dos temas que fazem parte dos planos "verdes" de longo prazo de inúmeras cidades. Elas procuram estimular a sua economia dentro do paradigma da sustentabilidade, e mitigar os seus impactos através da introdução de áreas verdes multifuncionais. Boston, nos Estados Unidos, que além da infraestrutura verde planeja reduzir o consumo de energia, gerar energia de fontes renováveis, promover transportes "limpos" (não poluentes) e fazer zoneamentos com áreas de usos múltiplos e edifícios "verdes". ${ }^{18}$

Atualmente o tema das mudanças climáticas tem tido maior visibilidade devido ao aumento na freqüência e força das tempestades, dos ventos, das ressacas marítimas, e de períodos de secas prolongadas. Esses eventos quando ocorrem em áreas urbanizadas tomam proporções com alto potencial destrutivo, devido à forma como a ocupação interferiu nos processos e fluxos naturais. As enchentes e

\footnotetext{
${ }^{18}$ Conferência de Kairos Shen e James Hunt: The Greening Boston, no seminário internacional Ecological Urbanism - Alternative and Sustainable Cities of the Future, em Harvard, 2 de abril de 2009.
} 
deslizamentos são devastadores, com prejuízos econômico-financeiros, sociais e ambientais, muitas vezes irrecuperáveis (Brandão, 2004; Coelho Netto, 2005; Coelho Netto, 2007).

A infraestrutura verde pode contribuir para a adaptação de áreas urbanas para enfrentar ocorrências climáticas ao converter áreas monofuncionais que causam impactos ecológicos em elementos que mimetizam os processos naturais. Além disso, a infraestrutura verde traz benefícios reais para as pessoas, ao transformar a paisagem urbana em áreas vivas, que aliam natureza, arte e cultura local. Privilegia os transportes "limpos", pedestres e bicicletas, o que colabora para a transição para uma economia de baixo carbono.

O desenvolvimento de infraestrutura verde em diversas escalas possibilita que 0 desenvolvimento se dê em bases sustentáveis, uma vez que é fundamentada em ciência robusta e no conhecimento do suporte natural (geológico, hidrológico e biológico) e cultural (social, circulatório e metabólico). Oferece serviços ecossistêmicos e mantém ou restabelece conexões fundamentais como os fluxos dos rios, da biodiversidade entre as áreas vegetadas, e das pessoas através de uma rede de transportes alternativos de baixo impacto (Ahern, 2007). 


\section{REFERÊNCIAS}

Ahern, Jack. Green Infrastructure for Cities: The Spatial Dimension. In: Cities of the Future - Towards Integrated Sustainable Water Landscape Mangement, (orgs.) Novotny, V. e Brown, P. IWA Publishing, London, 2007. pp. 267-283.

Ahern, Jack. Sustainability, Urbanism and Resilience. Palestra na Primeira Conferência de Humanidades e Indústria Criativa, Universidade de Tecnologia Nacional Chyn-Yi, Taichung, Taiwan, 4 de junho de 2009. pp. 4-22.

Alberti, Marina. Advances in Urban Ecology. Springer, New York, 2008.

Almeida, Claudia M., CÂMARA, Gilberto e MONTEIRO, Antonio M.V. Geoinformação em Urbanismo: Cidade Real X Cidade Virtual. Oficina de Textos, São Paulo, 2007.

Beatley, Timothy. Green Urbanism, Island Press, Washington, 2000.

Benedict, Mark A., e McMahon, Edward T.. Green Infrastructure - Linking Landscapes and Communities. Island Press, Washington, 2006.

Bolund, Per e Hunhammar, Sven. "Ecosystem Services in Urban Areas." In: Ecological Economics. Elsevier, Washington , 1999. pp. 293-301.

Boucinhas, Caio. "Espaço Público e Projeto Participativo." In: Cidade: Impasses e Perspectivas. (orgs.) GITAHY, Maria I.C.C.e LIRA José T.C. FAUUSP/Annablume/FUPAM, São Paulo, 2007. pp. 177-193.

Boutaud, Aurélien e Natacha Gondran. L'Empreinte Écologique. Éditions La Découverte, Paris, 2009.

Brandão, Ana Maria de P. M. "Clima Urbano e Enchentes na Cidade do Rio de Janeiro." In: Impactos Ambientais Urbanos no Brasil. (orgs.) Guerra, A. J. T. e Cunha, Sandra B. Editora Bertrand Brasil Ltda., Rio de Janeiro, 2004. pp. 47-109.

Coelho Netto, Ana Luiza. "A Interface Florestal-Urbana e os Desastres Naturais Relacionados à Água no Maciço da Tijuca: Desafios ao Planejamento Urbano numa Perspectiva Sócio-Ambiental." Revista do Departamento de Geografia 16, Rio de Janeiro, 2005. pp. 45-60.

Cormier, Nathaniel S. e Pellegrino, Paulo R.M. "Infra-Estrutura Verde: uma Estratégia Paisagística para a Água Urbana". Paisagem e Ambiente n. 25, São Paulo, 2008. pp. 127142.

Costa, Lucia, Farah, Ivete e Boucinhas, Caio. "Trialogue process in landscape design." 47th ISOCARP Congress - Urban Trialogues: Co-produtive ways to relate visionning and strategic urban projects. Antuérpia: ISOCARP, 2007. p. 19-23.

Dunnett, Nigel e Clayden, Andy. Rain Gardens. Timber Press, Inc., Portland, Oregon, 2007.

Elmqvist, Thomas. "Natural capital and indicators of ecosystema services and biodiversity in urban landscapes". Palestra no URBIO 2010 - Conferência de Biodiversidade Urbana e Projeto, In: Proceedings of teh 2nd International Conference of Urban Biodiversity and Desing. Nagoya, Japão, 18-22 de maio de 2010. pp.38-39

Farr, David. Sustainable Urbanism - Urban design with nature. John Wiley \& Sons, Inc. Hoboken, NJ, 2008. 
Forman, Richard T.T. e Godron, Michel. Landscape Ecology. John Wiley \& Sons, Inc., New York, 1986.

Forman, Richard T.T. Land Mosaics - The Ecology of Landscapes and Regions. Cambridge, 1995.

Forman, Richard T.T. "Urban ecology and the arrangement of nature in urban regions". In: Ecological urbanism. Mostafavi, Mohsen e Doherty, Gareth (eds.). Harvard University e Lars Publishers, 2010. pp. 312-323.

Frischenbruder, Marisa T. M. e Pellegrino, Paulo. "Using greenways to reclaim nature in Brazilian cities." Landscape and Urban Planning Nos. 1-4, 2006. pp. 67-78.

Geddes, Patrick. Cidades em Evolução. Tradução: Marai Jose F. de Castilho.: Papirus Editora, Campinas, 1994. (1a. ed. 1915),

Girling, Cynthia e Kellett, Ronald. Skinny Streets \& Green Neighborhoods - Design for Environment and Community. Island Press, Washington, 2005.

Herzog, Cecilia P. Guaratiba Verde: subsídios para o projeto de infraestrutura verde em área de expansão urbana na cidade do Rio de Janeiro. Dissertação de Mestrado, Universidade Federal do Rio de Janeiro, Faculdade de Arquitetura e Urbanismo, Programa de Pós-Graduação em Urbanismo/PROURB, Rio de Janeiro, 2009.

Herzog, Cecilia P. Green infrastructure as a strategy to reinstate resilience to an urban watershed in Rio de Janeiro, Brazil. In: Sessão paralela - Intelligent Urban Fabric. $1^{\text {st }}$ World Congress on Cities and Adaptation to Climate Change. Resilient Cities 2010. Bonn, 28-30 de maio de 2010. Disponível em http://resilientcities.iclei.org/bonn2010/program/sunday-30-may/parallel-sessions-g/\#c194

Hough, Michael. City and Natural Process. Van Nostrand Reinhold Company, Berkshire, 1984.

Hough, Michael. "Design with city nature: an overview of some issues." In: The Ecological City. (orgs.), Platt, R.H., ROWNTREE, R.A. e MUICK, P. C. The Univerisity of Massachusetts Press, Amherst, 1994. pp. 40-48

Howard, Ebenezer. Garden Cities of To-Morrow. The M.I.T. Press, Cambridge, 1973. (1a. edição em 1898)

Ignatieva, Maria et al. How to Put Nature into our Neighbourhoods. Vol. 35. Manaaki Whenua Press, Landcare Research New Zealand Ltd, Lincoln, 2008.

Ignatieva, Maria. "Planning and design of ecological networks in urban areas". Palestra no URBIO 2010 - Conferência de Biodiversidade Urbana e Projeto, In: Proceedings of teh 2nd International Conference of Urban Biodiversity and Desing. Nagoya, Japão, 18-22 de maio de 2010. pp.24-26.

Imbert, Dorothée. Aux Fermes, Citoyens! In: In: Ecological urbanism. Mostafavi, Mohsen e Doherty, Gareth (eds.). Harvard University e Lars Publishers, 2010. pp. 312-323.

Jacobs, Jane. The Death and Life of Great American Cities. Vintage Books (1a. ed. 1961), New York, 1992. 
Kinkade-Levario, Heather. Design for Water. New Society Publishers, Gabriola Island, 2007.

Marzluff, John M. et al (eds.). Urban Ecology - An international perspective on the interaction between humans and nature. Springer, New York, 2008.

McDonough, William e Braumgart, Michael. Cradle-to-Cradle. North Point Press, New York, 2002.

McHARG, lan L. Design with Nature. The Natural History Press, New York 1969.

Newman, Peter e Jennings, Isabella. Cities as Sustainable Ecosystems - Principles and Practice. Island Press, Washington 2008.

Newman, Peter, Beatley, Thimoty e Boyer, Heather. Resilient Cities - Responding to Peak Oil and Climate Change. Island Press, Washington, 2009.

Owen, David. Green Metropolis. Riverhead Books, New York, 2009.

Ribeiro, Helena. "Comunicação como Instrumento do Planejamento e da Gestão Ambientais." In: Novos Instrumentos de Gestão Ambiental Urbana. (orgs) Ribeiro, H. e Vargas, H. C. São Paulo: EDUSP, 2001. pp. 71-90.

Spirn, Anne W. The Authority of Nature: Conflict, Confusion, and Renewal in Design, Planning, and Ecology. In: Johnson, Bart R. e Hill, Kristina. Ecology and Design, Island Press, Washington, 2002. pp. 29-49.

Thompson, William J. e Sorvig, Kim. Sustainable Landscape Construction. Island Press, Washington, DC 2008.

Yu, Kongjian e Padua e Maria. The Art of Survival - Recovering Landscape Architecture. The Images Publishing Group Pty, Victoria, 2006. 